\title{
Postoperative quality-of-life assessment in patients with spine metastases treated with long-segment pedicle-screw fixation
}

\author{
Florian Bernard, MD, Jean-Michel Lemée, MD, PhD, Olivier Lucas, MD, and \\ Philippe Menei, MD, PhD \\ Department of Neurosurgery, CHU d'Angers, France
}

\begin{abstract}
OBJECTIVE In recent decades, progress in the medical management of cancer has been significant, resulting in considerable extension of survival for patients with metastatic disease. This has, in turn, led to increased attention to the optimal surgical management of bone lesions, including metastases to the spine. In addition, there has been a shift in focus toward improving quality of life and reducing hospital stay for these patients, and many minimally invasive techniques have been introduced with the aim of reducing the morbidity associated with more traditional open approaches. The goal of this study was to assess the efficacy of long-segment percutaneous pedicle screw stabilization for the treatment of instability associated with thoracolumbar spine metastases in neurologically intact patients.
\end{abstract}

METHODS This study was a retrospective review of data from a prospective database. The authors analyzed cases in which long-segment percutaneous pedicle screw fixation was performed for the palliative treatment of thoracolumbar spinal instability due to spinal metastases in neurologically intact patients. All of the patients included in the study underwent surgery between January 2014 and May 2015 at the authors' institution. Postoperative radiation therapy was planned within 10 days following the stabilization in all cases. Clinical and radiological follow-up assessments were planned for 3 days, 3 weeks, 6 weeks, 3 months, 6 months, and 1 year after surgery. Outcome was assessed by means of standard postoperative evaluation and oncological and spinal quality of life measures (European Organisation for Research and Treatment of Cancer Quality of Life Questionnaire Version 3.0 [EORTC QLQ-C30] and Oswestry Disability Index [ODI], respectively). Moreover, 5 patients were given an activity monitoring device for recording the distance walked daily; preoperative and postoperative daily distances were compared.

RESULTS Data from 17 cases were analyzed. There were no complications, and patients showed improvement in pain level and quality of life from the early postoperative period on. The mean ODI score was 62.7 (range 40-84) preoperatively, 35.4 (range 24-59) on postoperative Day 3, and 46.1 (range 30-76) at 3 weeks, 37.6 (range 25-59) at 6 weeks, 34.0 (range 24-59) at 3 months, 39.1 (range 22-64) at 6 months, and 30.0 (range 20-55) at 1 year after screw placement. The mean ODI was significantly improved in the first 45 days $(p<0.001)$. Improvement was also evident in scores for functional and symptomatic scales of the EORTC QLQ-C30. All patients underwent postoperative radiation therapy within 10 days (mean 7.5$)$. All patients $(n=5)$ with an activity monitoring device showed improvement in daily walking distance.

CONCLUSIONS Less-invasive palliative treatment for advanced spinal metastases is promising as part of a multidisciplinary approach to the care of patients with metastatic disease. The results of this study indicate that percutaneous surgery may allow for rapid improvement in quality of life and walking ability for patients with thoracolumbar instability due to spine metastases. Long-segment percutaneous screw fixation followed by early radiation therapy appears to be a safe and effective treatment option for providing solid and durable stability and improved quality of life for these patients.

https://thejns.org/doi/abs/10.3171/2016.9.SPINE16597

KEY WORDS spine; metastasis; quality of life; percutaneous osteosynthesis; oncology

ABBREVIATIONS EORTC QLQ-C30 = European Organisation for Research and Treatment of Cancer Quality of Life Questionnaire Version 3.0; MSD = metastatic spinal disease; ODI = Oswestry Disability Index; PMMA = polymethylmethacrylate; SINS = Spinal Instability Neoplastic Score; VAS = visual analog scale.

SUBMITTED May 22, 2016. ACCEPTED September 19, 2016.

INCLUDE WHEN CITING Published online March 24, 2017; DOI: 10.3171/2016.9.SPINE16597. 
$\mathrm{T}$ HE spine is a common site for secondary locations of cancers. ${ }^{3}$ It is also the most common location of bone metastases, ${ }^{24,30}$ which constitute a key element in tumor evolution. The prognosis for patients with vertebral metastases is mainly linked to the occurrence of neurological complications, with risks of tetra- or paraplegia and decreasing function in the setting of an already limited life expectancy. However, spinal pain related to usually spontaneous pathological fractures of unstable vertebrae must also be addressed.

In recent decades, there has been important progress in the medical treatment of cancer (chemotherapy and radiotherapy). Improved treatment has resulted in a considerable increase in the duration of survival, which in turn has increased the importance of optimal surgical management of bone lesions, including spinal metastases. With more treatment options available, the management of these patients should be focused on improving their quality of life. ${ }^{1}$ Currently, however, there is no consensus on the most effective treatment to improve quality of life in patients with unstable secondary lesions without clinical spinal cord compression.

Two types of surgical treatment may be considered for these patients: open spinal surgery and percutaneous spinal surgery. Conventional open surgery is normally not employed because it may result in a the delay in the implementation of radiotherapy ${ }^{33}$ and because healing is delayed in this patient population. ${ }^{7}$ Percutaneous spinal surgery (osteosynthesis, kyphoplasty, and vertebroplasty) has undergone steady development for 10 years. ${ }^{26,54}$ It is associated with less morbidity than conventional open surgery for restoration of spinal stability. Preservation of the paraspinal musculature limits postoperative pain and hospital stay, and percutaneous spinal surgery does not require a delay in radiotherapy. ${ }^{43,45,47,53,64}$

To our knowledge there is no study underway evaluating the quality of life of patients with surgically treated spinal instability due to metastases to the spine, whereas quality of life should be at the heart of management in these cases. The primary objective of this study was to evaluate the efficacy of long-segment percutaneous osteosynthesis with respect to quality of life for patients with spinal instability due to metastatic disease and to better integrate surgery in a multidisciplinary therapeutic strategy. The secondary objectives were to evaluate the effects of percutaneous surgery and conventional open surgery with respect to pain, complications, time lapse between surgery and radiotherapy for pain, and spinal instability due to dorsolumbar metastases without clinical spinal cord compression. In addition, we evaluated patients' daily walking distance with a Withings Pulse Ox activity monitor (Withings), used as a new measuring tool to assess the patient's daily quality of life.

\section{Methods}

This study was a retrospective review based on a prospective database. All patients included in the study underwent surgery for metastatic spinal disease (MSD) at our institution between January 2014 and May 2015. Participants gave their informed consent for use of their data in one or more studies based on this database prior to their inclusion in this study, but their treatment and follow-up otherwise did not vary from the regular treatment provided by our center.

\section{Data Collection}

The following preoperative data were collected: demographic details, primary tumor, Spinal Instability Neoplastic Score (SINS), ${ }^{22}$ Kostuik score,${ }^{37}$ visual analog scale (VAS) score for pain, ${ }^{2}$ and quality of life assessments with the European Organisation for Research and Treatment of Cancer Quality of Life Questionnaire Version 3.0 (EORTC QLQ-C30) and the Oswestry Disability Index (ODI). ${ }^{17}$ Radiological investigations, such as MRI, CT, and/or bone scans, provided data on pathological fracture. Intraoperative details recorded were operating time and amount of blood loss. Postoperative data collected were VAS scores, ambulatory status, EORTC QLQ-C30 scores, ODI scores, and length of hospital stay. The time to initiation of radiotherapy or chemotherapy and complications such as wound infection were also recorded.

Five patients who were allowed to walk preoperatively and had an SINS between 7 and 12 were given a Withings Pulse Ox activity monitor (Fig. 1) to assess walking distance (equipment provided by Withings). This device, which may be worn like a watch, can be connected to an Apple or Android smartphone and used to measure distance walked. It has recently been validated for medical research in free-living conditions. ${ }^{20}$ Results are integrated in secondary objectives, as an innovative connected approach to continuous assessment of the patient's quality of life.

\section{Inclusion Criteria}

We included patients who had MSD and met all of the following criteria: age $>18$ years, no previous spinal surgery, and no clinical or radiological evidence of infection. In all cases, the indication for surgery was spinal instability (including potential instability) evaluated using the SINS classification, ${ }^{63}$ without clinical cord compression, and with the presence of pathological fracture and intractable pain not responding to conservative oncological treatment. The pain related to the fractured vertebra had to be a prominent symptom. Patients with an SINS $>12$ had frankly unstable spines and were unable to walk. For patients with an SINS between 7 and 12 (potentially unstable spine), the Kostuik score of the most osteolytic vertebra was also considered. Patients with an SINS between 7 and 12 and a Kostuik score $>2$ were able to walk preoperatively. Patients younger than 18 years; those with primary bone tumors, cervical metastasis, or clinical spinal cord compression; and patients with contraindications to medical or surgical stabilization (blood platelet count $\geq 50,000$ / $\mathrm{mm}^{3}$, untreated local infection, respiratory insufficiency, obesity with a body mass index $[\mathrm{BMI}]>35 \mathrm{~kg} / \mathrm{m}^{2}$ ) were excluded from the study.

\section{Surgical Technique}

Patients underwent long-segment posterior spinal instrumentation without decompression using posterior 

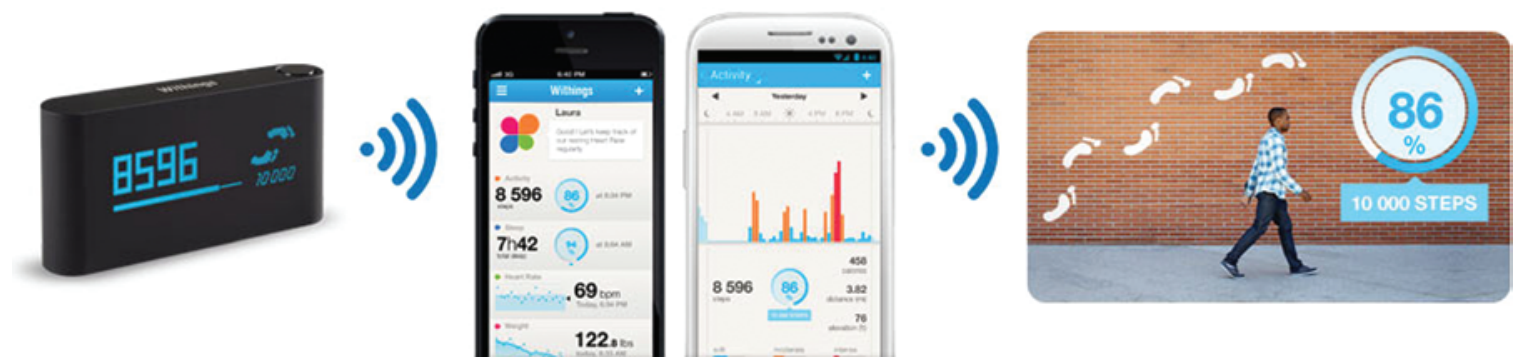

FIG. 1. Withings Pulse Ox activity monitor. Photograph courtesy of Withings

percutaneous spinal fixation using Medtronic Longitude instrumentation

Briefly, percutaneous pedicle screws were inserted 2 vertebrae above and 2 below. A true anteroposterior fluoroscopic view of the vertebrae was obtained. A trocar was engaged to the pedicle entry point and advanced into the pedicle until the tip of the trocar touched the medial pedicle wall on the anteroposterior view. Once this was achieved, a lateral image was obtained. On the lateral view, the tip of the trocar had to reach the posterior wall of the vertebral body to make sure that the trocar did not breach the medial pedicle wall. The trocar was then advanced to the middle of the vertebral body. A guidewire was then inserted and the trocar removed. Pedicle screws were inserted following guidewires, and the wires were removed once the screws were in position as guided by the lateral image. The same steps were repeated for the rest of the predetermined instrumented vertebra. At the end of the procedure, the rods were contoured and inserted. Nuts were then inserted and final tightening of the whole construct was performed followed by closure of the deep fascia and skin.

Subsequently, patients were offered optimal medical therapy, including chemotherapy and radiotherapy, in a multidisciplinary management approach. They were referred to an oncologist and radiotherapist for treatment of the primary tumor as well as for vertebral radiotherapy, according to treatment guidelines their primary cancer. All patients were followed up for a minimum period of 4 months from the time of surgery until the end of the study period.

\section{Statistical Analysis}

All statistical analyses were performed using commercially available SPSS software, version 17.0 (SPSS Inc.). Statistical analysis was carried out using independent ttest or chi-square test with statistical significance set at $p$ $<0.05$.

\section{Results}

\section{Demographic Characteristics}

During the 1-year study period, a total of 17 patients who underwent spinal surgery using posterior percutaneous spinal fixation for MSD met the criteria for inclusion in this study. Their baseline clinical characteristics and the preoperative details of their cases are summarized in Tables 1 and 2. Five of the patients had breast cancer, 5 had lung cancer, 3 had prostate cancer, 3 had colon cancer, and 1 had kidney cancer. There were 9 deaths during the study period. The average number of vertebral levels with pathological fractures was $2.6 \pm 1.6$ per patient. No patient required decompression surgery in addition to percutaneous long-segment fixation. The average operation time was 1 hour (range $0.5-1.5$ hours). The average blood loss was less than $0.2 \mathrm{~L}$. The average number of instrumented vertebrae was 5 . The average number of screws inserted per patient was 8 . No patient had significant anterior column deficiency requiring anterior column augmentation. The overall median survival was 11.0 months (range 4-16 months). All patients were alive 3 months after surgery, and 8 patients (47\%) were still alive at the end of the study period (May 2015).

\section{Adjuvant Treatment and Complications}

Radiotherapy was started within 10 days of surgery. The total dose was $30 \mathrm{~Gy}$, administered in 10 fractions. Treatments were delivered to a port that encompassed 1 vertebral body above and below the visible lesion. All patients received the complete radiotherapy course. The mean length of time from the index surgery to the initiation of radiotherapy was 7.5 days (range 5-10 days).

There were no perioperative complications, wound dehiscence, pulmonary complications, or screw-related injuries noted in this study. All patients were neurologically intact at follow-up. However, 2 patients had recurrences at a different site from the index level, requiring a second session of external beam radiotherapy ( $8 \mathrm{~Gy}$ in a single fraction, in each case).

\section{Pain and Functional Outcomes}

All patients suffered from moderate to severe pain preoperatively (mean 7.2 on a 10-point VAS). Within 1 week of the operative procedure, significant pain relief was reported by all patients (Table 1, Fig. 2). The mean preoperative VAS spinal pain score was 7.4 (range 6-10); the mean VAS pain scores obtained 3 days, 3 weeks, 6 weeks, 3 months, 6 months, and 1 year after surgery were 2.5 (range 0-5), 2.4 (range 0-3), 2.4 (range 1-3), 2.2 (range 0-4), 2.5 (range 1-4), and 2.4 (range $0-4$ ), respectively. Compared with the preoperative value, there was a significant reduction in mean pain score at 3 days, 3 weeks, 6 weeks, and 3 months after surgery ( $p<0.05$ for all comparisons).

The mean preoperative ODI score was 62.7 (range 40-84); the mean ODI scores obtained 3 days, 3 weeks, 6 weeks, 3 months, 6 months, and 1 year after surgery were 35.4 (range 24-59), 46.1 (range 30-76), 37.6 (range 25-59), 34.0 (range 24-59), 39.1 (range 22-64), and 30.0 
TABLE 1. Baseline clinical characteristics and procedure outcome measures

\begin{tabular}{|c|c|}
\hline Variable & Value \\
\hline No. of patients & 17 \\
\hline \multicolumn{2}{|l|}{ Age in yrs } \\
\hline Mean & 58 \\
\hline Range & $48-65$ \\
\hline \multicolumn{2}{|l|}{ Sex } \\
\hline Female & $10(58.9)$ \\
\hline Male & $7(41.1)$ \\
\hline \multicolumn{2}{|l|}{ Underlying pathology } \\
\hline Breast & $5(29)$ \\
\hline Lung & $5(29)$ \\
\hline Prostate & $3(18)$ \\
\hline Colon & $3(18)$ \\
\hline Kidney & $1(6)$ \\
\hline \multicolumn{2}{|l|}{ Kostuik score } \\
\hline Mean & 4.3 \\
\hline Range & $3-6$ \\
\hline Previous RT & $1(6)$ \\
\hline \multicolumn{2}{|l|}{ Follow-up (mos) } \\
\hline Mean & 12.7 \\
\hline Range & $4-16$ \\
\hline \multicolumn{2}{|l|}{ Preop pain (VAS score) } \\
\hline Severe $(7-10)$ & $12(71)$ \\
\hline Moderate (5-6) & $5(29)$ \\
\hline Mild (1-4) & 0 \\
\hline No pain & 0 \\
\hline \multicolumn{2}{|l|}{ Postop pain, Day 21 (VAS score) } \\
\hline Severe $(7-10)$ & 0 \\
\hline Moderate (5-6) & 0 \\
\hline Mild (1-4) & $16(94)$ \\
\hline No pain & $1(6)$ \\
\hline \multicolumn{2}{|l|}{ Op variables } \\
\hline \multicolumn{2}{|l|}{ Blood loss (ml) } \\
\hline Mean & 125 \\
\hline Range & $50-180$ \\
\hline \multicolumn{2}{|l|}{ Op time (mins) } \\
\hline Mean & 58 \\
\hline Range & $30-90$ \\
\hline \multicolumn{2}{|l|}{ Hospital stay (days) } \\
\hline Mean & 3.4 \\
\hline Range & $2-5$ \\
\hline \multicolumn{2}{|l|}{ Time to start RT (days) } \\
\hline Mean & 7.5 \\
\hline Range & $5-10$ \\
\hline \multicolumn{2}{|l|}{ Time to start chemo (days) } \\
\hline \multicolumn{2}{|l|}{ Complications } \\
\hline Mean & 15 \\
\hline Range & $10-20$ \\
\hline
\end{tabular}

CONTINUED IN NEXT COLUMN »
» CONTINUED FROM PREVIOUS COLUMN

TABLE 1. Baseline clinical characteristics and procedure outcome measures

\begin{tabular}{ll}
\hline \multicolumn{1}{c}{ Variable } & Value \\
\hline Complications (continued) & \\
\hline $\begin{array}{l}\text { Adjacent-level fracture responsive to repeat stabili- } \\
\text { zation }\end{array}$ & 0 \\
\hline Progression of disease requiring RT & $2(12)$ \\
\hline Progression of disease requiring decompression & 0 \\
\hline Asymptomatic screw pullout & 0 \\
\hline Wound infection & 0 \\
\hline
\end{tabular}

Chemo = chemotherapy; RT = radiotherapy.

Data are number of patients (\%) unless otherwise indicated.

(range 20-55), respectively. ODI significantly improved during the 45 days immediately after surgery $(\mathrm{p}<0.001)$ (Fig. 2C).

Concerning EORTC QLQ-C30 (Tables 3 and 4), postoperative evaluation showed improvement on the scales assessing the following functional areas: physical functioning (change from preoperative value to Day 45 value $14.7 \pm 11.1)$, role functioning $(37.1 \pm 26.5)$, emotional func-

TABLE 2. Baseline SINS characteristics

\begin{tabular}{lc}
\hline \multicolumn{1}{c}{ Characteristic } & Value \\
\hline Location & \\
\hline Junctional (O-C2, C7-T2, T11-L1, L5-S1) & $11(64)$ \\
\hline Mobile spine (C3-6, L2-4) & $3(18)$ \\
\hline Semirigid (T3-10) & $3(18)$ \\
\hline Rigid (S2-5) & 0 \\
\hline Bone lesion & $11(65)$ \\
\hline Lytic & $5(29)$ \\
\hline Mixed (lytic/blastic) & $1(6)$ \\
\hline Blastic & \\
\hline Radiographic spinal alignment & 0 \\
\hline Subluxation/translation present & $10(6)$ \\
\hline De novo deformity & $7(94)$ \\
\hline Normal alignment & \\
\hline VB collapse & $11(64)$ \\
\hline$>50 \%$ collapse & $5(29)$ \\
\hline$<50 \%$ collapse & $1(6)$ \\
\hline No collapse w/ $>50 \%$ VB involved & 0 \\
\hline No collapse w/ <50\% VB involvement & \\
\hline Posterolateral involvement & $4(24)$ \\
\hline Bilateral & $12(70)$ \\
\hline Unilateral & $1(6)$ \\
\hline None & \\
\hline SINS, aggregate score & 12.4 \\
\hline Median & $8-16$ \\
\hline Range & \\
\hline &
\end{tabular}

$\mathrm{O}=$ occiput; $\mathrm{VB}=$ vertebral body.

Data are number of cases (\%) unless otherwise indicated. 

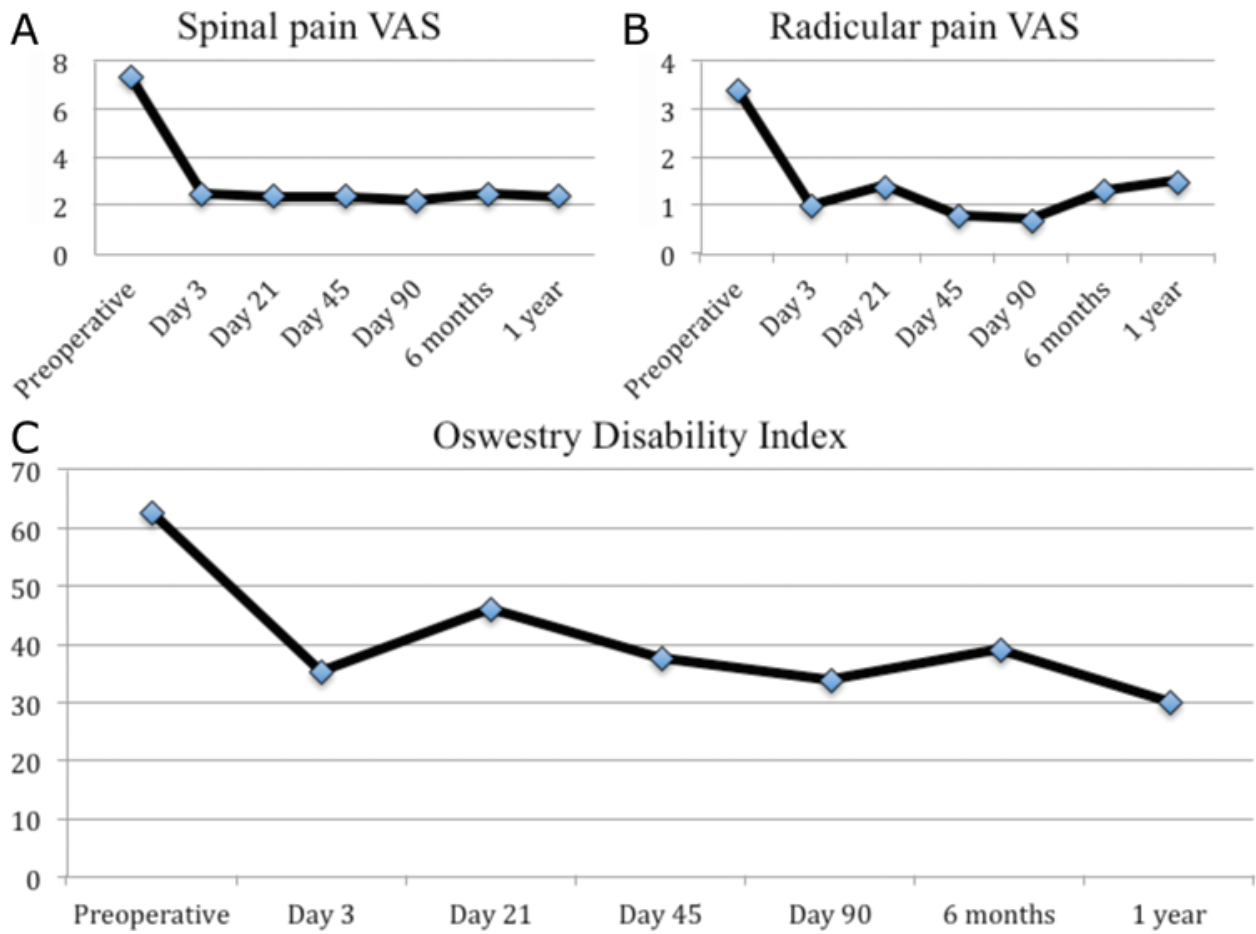

FIG. 2. Mean VAS scores for spinal pain (A) and radicular pain $(\mathbf{B})$ and mean ODI scores $(\mathbf{C})$ at different time points. Day 0 refers to preoperative assessments (precise timing relative to day of surgery may vary). Figure is available in color online only.

tioning $(23.1 \pm 26.0)$, cognitive functioning $(8.4 \pm 13.0)$, and social functioning $(32.0 \pm 27.2)$. Symptomatic scales such as fatigue $(-15.6 \pm 21.0)$, pain perception $(-38.9 \pm$ 14.8), insomnia (-17.2 \pm 36.1$)$, appetite loss $(0 \pm 20.1)$, and constipation $(-2.8 \pm 9.6)$ were also improved.

All patients were able to walk on postoperative Day 1. None of the patients were bedridden after the surgery. Regarding the 5 patients allowed to walk preoperatively, whose daily walking was measured with the activity

TABLE 3. Summary of changes in EORTC QLQ-C30 scores between the preoperative and Day 45 assessments

\begin{tabular}{lrrl}
\hline \multicolumn{1}{c}{ Measure } & Mean Change & SD & Clinical Significance \\
\hline Global health status & 14.7 & 11.1 & Improving QOL \\
\hline Pain & -38.9 & 14.8 & Improving QOL \\
\hline Role functioning & 37.1 & 26.5 & Improving QOL \\
\hline Social functioning & 32.0 & 27.2 & Improving QOL \\
\hline Physical functioning & 29.2 & 21.3 & Improving QOL \\
\hline Emotional functioning & 23.1 & 26.0 & Improving QOL \\
\hline Insomnia & -17.2 & 36.1 & Improving QOL \\
\hline Fatigue & -15.6 & 21.0 & Improving QOL \\
\hline Cognitive functioning & 8.4 & 13.0 & Improving QOL \\
\hline Financial difficulties & -5.5 & 18.0 & Improving QOL \\
\hline Dyspnea & -2.8 & 9.6 & Improving QOL \\
\hline Constipation & -2.8 & 9.6 & Improving QOL \\
\hline Diarrhea & -2.8 & 9.6 & Improving QOL \\
\hline Appetite loss & 0.0 & 20.1 & Improving QOL \\
\hline
\end{tabular}

$\mathrm{QOL}=$ quality of life. monitor, all showed improvement in their daily walking distance after surgery (Table 5). The differences between the preoperative values for distance walked daily and the values for postoperative Day 21 (mean difference +812.5 m), Day 45 (+932.5 m), and Day 90 (+962.5 m) were all statistically significant $(\mathrm{p}<0.05)$.

As shown in Table 6, correlations between Day 45 pain and Day 21 spinal pain $(r=0.01$ and 0.03 , respectively) and daily walking distance were statistically significant $(\mathrm{p}<0.05)$. A correlation between the Day 45 daily walk perimeter and the following scales was found but was not statistically significant: the functional scales for physical functioning $(r=0.82)$ and role functioning $(r=0.14)$ and the symptomatic scales for fatigue $(r=0.39)$ and pain perception $(r=0.70)$.

\section{Discussion}

The incidence of skeletal metastases is as high as $70 \%$

TABLE 4. Summary of EORTC QLQ C30 functional scale scores at 45 days after surgery

\begin{tabular}{lcccccc}
\hline \multicolumn{1}{c}{ Measure } & Min & Q1 & Median & Mean & Q3 & Max \\
\hline Physical functioning & 46.70 & 51.15 & 56.75 & 55.10 & 60.00 & 60.00 \\
\hline Role functioning & 33.30 & 58.15 & 66.85 & 66.70 & 75.00 & 100 \\
\hline Pain & 16.70 & 30.10 & 41.00 & 37.40 & 50.00 & 50.00 \\
\hline Fatigue & 22.20 & 30.40 & 50.50 & 50.50 & 69.50 & 77.80 \\
\hline Global health status & 66.70 & 66.70 & 66.70 & 68.80 & 68.80 & 75
\end{tabular}

Max = maximum value; $\min =$ minimum value; $\mathrm{Q} 1=$ first quartile; $\mathrm{Q} 3=$ third quartile. 
TABLE 5. Daily walking distance for the 5 patients allowed to walk preoperatively

\begin{tabular}{lrcc}
\hline & \multicolumn{3}{c}{ No. of Meters } \\
\cline { 2 - 4 } Statistic & Day 21 & Day 45 & Day 90 \\
\hline Min & 500.0 & 700.0 & 850.0 \\
\hline Q1 & 687.5 & 812.5 & 887.5 \\
\hline Median & 775.0 & 890.0 & 900.0 \\
\hline Mean & 812.5 & 932.5 & 962.5 \\
\hline Q3 & 900.0 & 1010.0 & 975.0 \\
\hline Max & 1200.0 & 1250.0 & 1200.0 \\
\hline
\end{tabular}

Boldface type indicates a statistically significant improvement in comparison with the mean preoperative value of $478 \mathrm{~m}$ (Welch t-test, $p<0.05$ ).

in autopsies of cancer patients, and the spine is the most common site of bony metastases. ${ }^{11,30}$ Most patients with spinal metastases present with spinal instability and back pain due to pathological fracture(s). ${ }^{28,31}$ Approximately 5\% to $10 \%$ of these patients present with spinal cord compression resulting in neurological deficit. ${ }^{34,52}$ Both instabilityrelated pain and neurological deficit can significantly affect quality of life..$^{59}$ Patients are likely to be bedbound because of intractable pain and neurological deficits. Immobilization in bed can lead to complications, including orthostatic pneumonia, pressure sores, urinary tract infection, thromboembolism, and joint contractures..$^{14,15}$ The treatment of spinal metastases is usually palliative, aiming to provide pain relief, maintenance or recovery of neurological function, local durable tumor control, spinal stability, and improved quality of life,, 35 although in rare cases, patients who present with isolated spinal metastases at an early stage may be treated with radical resection. The treatment for patients with spinal instability due to metastatic disease often involves nonoperative palliative care due to the serious prognosis associated with their condition. Decisions regarding surgical treatment in such cases are generally based on 3 main factors: surgical indication, surgical risk, and life expectancy. The goal of surgery in these cases is unique: improving the patients' quality of life promptly.

\section{Surgical Indications and Complications}

The indications for surgery are the presence of spinal instability with and without neurological deficit. ${ }^{5,61}$ However, the benefits of the surgery should outweigh the surgical risks when deciding on surgical intervention in this group of patients. Mechanical instability represents an independent indication for stabilization. Radiation, although effective for local tumor control, has no impact on spinal stability, ${ }^{38,63}$ and mechanical instability serves as an indication for spinal immobilization regardless of oncological assessment. The Spinal Oncology Study Group has defined spinal instability as the "loss of spinal integrity as a result of a neoplastic process that is associated with movementrelated pain, symptomatic or progressive deformity, and/or neural compromise under physiologic loads." ${ }^{22,23}$ The assessment of spinal instability is dependent on both clinical and radiographic criteria. All patients with clear manifestations of thoracic or lumbar mechanical instability require stabilization because mechanical pain does not improve
TABLE 6. Correlation between daily walking distance and other QOL measures (EORTC QLQ C30 global and functional scales and VAS spinal pain scores)

\begin{tabular}{lccc}
\hline \multicolumn{1}{c}{ Scale \& Time Point } & $p$ Value & $r$ & $95 \% \mathrm{Cl}$ \\
\hline Physical functioning, Day 45 & 0.18 & 0.82 & -0.66 to 1 \\
\hline Role functioning, Day 45 & 0.86 & 0.14 & -0.95 to 0.97 \\
\hline Pain, Day 45 & 0.30 & 0.70 & -0.80 to 0.70 \\
\hline Fatigue, Day 45 & 0.60 & 0.39 & -0.91 to 0.98 \\
\hline Global health status, Day 45 & 0.09 & 0.91 & -0.41 to 1 \\
\hline VAS, spinal pain, Day 21 & 0.01 & 0.99 & -0.48 to 1 \\
\hline VAS, spinal pain, Day 45 & 0.03 & 0.97 & 0.09 to 1 \\
\hline
\end{tabular}

* Based on Welch 2-sample t-test.

with steroid therapy and radiation does not restore spinal stability. ${ }^{21,33,41}$ Stabilization is usually treated by an orthopedic treatment (brace) or surgery (open surgery, percutaneous osteosynthesis, kyphoplasty, or vertebroplasty).,12,13 Depending on the degree of instability and tumor infiltration, instrumented stabilization or vertebroplasty can be performed.

\section{Brace}

External stabilization with orthoses is used in selected cases when surgery is not an option or has been scheduled for a later date. ${ }^{21}$ Many kinds of orthoses have been developed to provide the best possible biomechanical stability at different spinal levels. Most data derive from spine injury series. To our knowledge, no systematic reviews exist regarding the outcomes of orthoses in pathological fractures. But our single-center experience shows that the use of orthoses is associated with a lot of skin complications as well as psychological deterioration and lack of satisfactory pain relief.

\section{Vertebroplasty/Kyphoplasty}

Vertebroplasty was first described in 1987 by Galibert et al. ${ }^{25}$ in the treatment of vertebral angiomas. Later, indications for the use of this method were extended to osteoporotic fractures and vertebral body metastases. The aim is to inject a radiopaque polymethylmethacrylate (PMMA) cement in the vertebral body through a trocar. But there are contraindications: spinal cord compression, invasion of the vertebral body's posterior wall, vertebral collapse $>75 \%$, or recent fracture that increases the risk of cement leakage. Cement leakage is the principal complication of vertebroplasty and kyphoplasty. There are also mechanical complications: spinal cord or radicular compression and pulmonary embolism.

Kyphoplasty offers the additional advantage of realigning the spinal column and restoring height of fractured vertebrae, which may help to decrease the risks of cement leakage. The principle is the same: PMMA injection in the vertebral body after restoring height with balloons of 10,15 , or $20 \mathrm{ml}$ (functions of the height and level to be treated). The aim is to create a cavity to inject thicker cement, decreasing cement's leakage risk. The balloon also allows treatment of collapsed vertebrae. The only absolute contraindication is spinal cord compression. Posterior wall 
invasion is a relative contraindication, because the risk of cement leakage is limited. In a meta-analysis, Papanastassiou et al. ${ }^{48}$ observed a $41 \%$ rate of cement leakage for patients treated with vertebroplasty versus $18 \%$ for those treated with kyphoplasty. In some cases, kyphoplasty and vertebroplasty could be associated with percutaneous osteosynthesis to reach 2 aims: spinal stability and reduction. Gross instability is related to tumor infiltration and fracture of posterior elements that include the pedicle and the joint and may require additional fixation to restore adequate vertebral column support and to prevent foraminal collapse with axial loading. Indeed, as in traumatology, we should not underestimate instability that is insufficiently treated by kypho-/vertebroplasty alone. Kyphoplasty or vertebroplasty provide fairly durable and consistent pain relief for patients with tumors that infiltrate only the vertebral body, without significant involvement of the posterior elements and an epidural tumor burden. If the tumor infiltrates the posterior elements or significantly extends into the spinal canal, an instrumented stabilization is generally required to restore stability and provide adequate pain relief.

\section{Percutaneous Fixation}

Historically, percutaneous osteosynthesis was offered in combination with an anterior approach for the treatment of spinal degenerative diseases. ${ }^{39}$ Currently employed in traumatology, this method is the first-intention treatment of neurologically intact or polytrauma patients with spinal fracture. ${ }^{29,61}$ Ancillary reduction allows distraction, i.e., lordosis, to achieve the same goal as open surgery. ${ }^{40}$ Moreover, adequate screw positioning and kyphosis reduction can be achieved easily through direct fluoroscopic exploration. In the series of Vanek et al., ${ }^{60}$ screw position was too medial in only $2.8 \%$ of screws placed percutanously compared with a rate of $7.4 \%$ of screws placed in open surgery.

In older patients with osteoporosis and multiple bone lesions, the principal biomechanical risk is the failure of surgical instrumentation. Many cancer patients have significant osteoporotic bone and poor bone quality. In biomechanical and clinical studies, cement augmentation of pedicle screws - using a variety of techniques, screw types, and cements - has been shown to provide increased screw fixation and strength. Burval et al. ${ }^{6}$ showed increased pedicle screw pullout loads in osteoporotic human cadavers with transpedicular PMMA augmentation. Choma et al. ${ }^{9}$ used cement augmentation in a biomechanical model designed to simulate pullout, transverse, and moment load.

In the last few decades, efforts have been made to improve the clinical outcome of operations, essentially by minimizing the invasive nature of the open approach and by reducing the segments of motion involved in the fusion area. However, a high failure rate has also been reported with short-segment constructs. According to Moussazadeh et al., ${ }^{44}$ short-segment percutaneous pedicle screw fixation with vertebral body cement augmentation can provide the required stabilization of the anterior and posterior spinal elements.

Our decision to carry out a long stabilization in the patients presented here, instead of a short implant, was influenced by multiple considerations. In view of the poor clinical condition of these patients and the poor prognosis, one of the most important considerations is to avoid any type of additional conservative treatment or bed rest, especially in cases with involvement of multiple vertebrae. Any kind of orthosis caused the worsening of patient's postural problems and walking ability. Several factors are regarded as being potential causes for short-implant failure; the most important factor seems to be inadequate anterior column support. Therefore, in cases of real or impending anterior column deficiency, such as severe tumor involvement of the vertebral body, a short construct could prove to be an almost certain failure. The real issue when approaching an unstable or potentially unstable vertebral lesion seems to be how best to support the spine by avoiding either extremely demanding or invasive procedures or too simple constructs, which could increase the risk of implant failure. There are currently no published guidelines for the proper selection of patients suitable for their use.

With regard to the segments of motion being compromised, the problem specifically affects the lumbar spine area. In fact, the proximal lengthening of the fixation to the thoracic tract is not very relevant biomechanically, because the thoracic segments are barely mobile; therefore, a longer fixation does not significantly influence the overall movement of the spine. Quite a different matter, from a biomechanical perspective, is the distal length of the implant to a lower lumbar motion segment. If we compare the short and long constructs, the real difference between the 2 systems, in terms of global movement of the spine, is the loss of only 1 more distal segment of motion, which is suppressed in the long stabilization. In our cases, there are obvious losses of a certain degree of lumbar spine motion, although the patients who were treated with long implants did not refer to symptoms pertaining to spinal stiffness. We think that, in these particular patients, it could be more reasonable to choose to lose 1 or more segments of motion.

Considering the limited life expectancy of most patients with spinal metastases, the main goal is to improve quality of life by stabilizing the spine, whether it is with long-segment fixation or short-segment fixation with cement augmentation.

\section{Open Surgery}

Concerning open surgery, previous reports from the literature $^{28,32,57}$ showed improvement of functional status in terms of both pain management and Frankel grade. In a study by Chong et al., ${ }^{10}$ the mean postoperative VAS score for pain improvement was 3.2, and 20 (64\%) of the 63 patients with a preoperative Frankel grade lower than E reported improvement of 3 or more points. In that study, $32 \%$ of these patients showed improvement of at least 1 grade on the Frankel scale, 76 (93\%) of the 82 patients who had ambulatory function preoperatively were able to maintain it after surgery, and $10(43 \%)$ of the 23 patients who were nonambulatory preoperatively regained ambulatory function postoperatively.

However, in addition to having positive outcomes, open surgery in patients with spinal metastases is associated with a higher complication rate. ${ }^{49,55}$ Patients often are in poor general condition as a consequence of their primary disease process as well as the adverse effects of chemotherapy and radiotherapy. The postoperative wound infection rate can be up to $12 \%$ for this group of patients. ${ }^{27}$ In patients who undergo radiotherapy prior to 
surgery, the risk of dehiscence and wound infection is as high as $32 \% .{ }^{27}$ Minimally invasive surgery can reduce the infection rate because it reduces the physiological insult, decreases the recovery time, and minimizes the morbidity associated with a more conventional open approach. O'Toole et $\mathrm{al} .{ }^{46}$ concluded in their study that minimally invasive spinal surgery may reduce postoperative wound infections by 10 -fold compared with open surgery. In our study, there was no wound breakdown or infection in any patient.

Fusion systems have evolved and now offer a variety of treatment options to be used by health care professionals. However, the patient with cancer often has limited reserves, so a major consideration in the choice of therapy is to avoid complications. Therefore, careful patient selection and an overall multidisciplinary approach to the mastery of surgical techniques are both required. Increasing patient survival and improving quality of life are the ultimate goals of treatment. However, a need for palliative therapy still exists in the majority of oncological surgery cases.

\section{Life Expectancy}

Life expectancy, which depends on the nature of the primary tumor, the extent of the metastasis, and the patients' general condition, ${ }^{59}$ plays a major role in decisions regarding the surgical treatment of spinal instability associated with metastatic disease. Most surgeons recommend that surgery should be offered when life expectancy exceeds 3 months..$^{5,55,58}$ Tokuhashi et al. ${ }^{58}$ suggested that surgery should be reserved for patients with expected survival of more than 6 months. These limits are suggested mainly because open procedures are associated with significant morbidity and risk of mortality in patients with advanced spinal metastasis. However, in the absence of any surgical intervention, these patients may suffer from intractable instability pain and poor quality of life. They will be more likely to be bedridden and to develop several complications as a result of immobilization in bed due to severe instability pain. In the current study, all patients received treatment regardless of their life expectancy, and based on our experience with these patients, we would like to see spinal percutaneous stabilization integrated as an additional path of palliative care for patients with advanced metastatic disease.

\section{Pain and Functional Outcomes}

Long-segment percutaneous fixation resulted in significant reduction of pain in our study, as demonstrated by the reduction in the mean VAS score for pain (from 7.4 preoperatively to 2.5 on postoperative Day 45, $\mathrm{p}<0.05$ ). Despite having less than 6 months of life expectancy, these patients could sit up and had better ambulation after stabilization of their pathological fractures. On average, patients were able to walk 1 day after surgery in this study. This rapid recovery from surgery is attributed to the minimal muscle disruption in percutaneous surgery. ${ }^{19,35}$ Even a short duration of survival with preservation of the ability to ambulate is very meaningful for these dying patients.

To our knowledge no previous studies have been performed with prospectively collected data to assess the initial quality of life in patients with MSD treated exclusively with percutaneous spinal surgery. Our study demonstrates that spinal surgery improves quality of life for selected patients with metastatic disease of the spine. Quality of life after surgery, assessed by the EORTC QLQ-C30 and ODI patient-reported outcome measures and VAS pain score, improved rapidly and these improvements were sustained for up to 1 year in those patients who survived. All patients maintained the ability to walk, and further spinal surgery for disease progression was uncommon ( $0 \%$ in our series compared with $3.7 \%$ in the study by Choi et al. ${ }^{8}$ ). The study by Rades et al. ${ }^{51}$ was a large cohort study, but it was retrospective and did not assess patients' quality of life. The authors demonstrated that the ability to walk after radiotherapy was associated with primary tumor type, pretreatment duration of symptoms, presence of visceral metastases, motor function, and ECOG (Eastern Cooperative Oncology Group) functional status.

\section{Quality of Life in Free-Living Conditions}

The new wave of consumer-level activity monitors offers exciting possibilities for individuals, clinicians, and researchers. Although the activity monitor that we used is not specifically designed for clinical use, its low cost (around \$100 [US]) and its ability to assess data continuously ( 24 hours a day) in the patient's home are very interesting. Moreover Ferguson et al. ${ }^{20}$ have shown that the Withings Pulse consumer-level activity monitor is highly accurate for the measurement of steps in free-living conditions. Clinical surveillance at home with a connective approach may be useful with respect to limiting psychological deterioration and expensive hospitalization as well as improving liaisons between patients and the hospital.

Many quality-of-life assessments have been reported for spinal tumor and cancer patients. ${ }^{14,16,36,41,56}$ Rades and colleagues ${ }^{51}$ considered the ability to walk the most important outcome measure and suggested a management algorithm based on the likelihood of walking after treatment, discouraging active intervention in patients who were unlikely to walk again. Indeed, the daily walking distance may be a good parameter for ongoing measurement of a patient's quality of life because it can be easily assessed with a connected activity monitor, allowing an evaluation of the patient's physical activity at home. The more the patient walks, the better his or her quality of life, especially for spinal tumor patients. It is important to assess the impact of surgery while considering the patient as a whole and being aware that these are patients for whom spinal disease is only one of several factors that may affect quality of life. In the past, survival, pain, and complication rates were the key parameters by which surgery for spinal metastases was judged by surgeons and physicians, and there were scant data on patients' reported oncological and spinal outcome measures for surgery of spinal metastases. Falicov et al. ${ }^{18}$ reported on a series of 85 patients who had improvements in pain and EORTC QLQ-C30 questionnaire results at 1 year after surgery. Quan et al. ${ }^{50}$ reported on 118 patients with improved QLQ-C30 scores at 1-year follow-up, and $\mathrm{Wu}$ et al. ${ }^{65}$ described 46 surgical patients with improvements in the Functional Assessment of Cancer Therapy questionnaire at 9 months after surgery. The present study represents the first published assessment of 
early postoperative quality of life after long-segment spinal fixation in patients with spinal metastases.

There were a few limitations in this study. The primary tumors in these 17 patients with spinal metastases were heterogeneous. Different primary tumors have different biological behavior and prognoses. Moreover, the number of patients included is small. However our results indicate that percutaneous surgery is effective and safe for the palliative management of spinal instability due to metastatic disease. This treatment option allows quality of life and pain relief to be improved and could be included in the NOMS (neurologic, oncologic, mechanical, and systemic) framework. ${ }^{38}$

Our results demonstrate that percutaneous spinal stabilization can improve quality of life in MSD patients during the first postoperative month, a finding that should ultimately guide surgical decision making. Pain reduction and an appropriate amount of ambulation with a low rate of complications following surgery are important because achieving these goals is likely to motivate patients to continue with adjuvant therapy.

\section{Conclusions}

Less-invasive palliative treatment based on a multidisciplinary approach holds promise for patients with advanced spinal metastases. Treatment was divided into percutaneous long-segment pedicle-screw stabilization for instability and tumor control with radiotherapy/chemotherapy. This strategy provided rapidly improved functional outcome with a low risk of complications. Use of a multidisciplinary approach can improve quality of life for fragile patients with spinal metastases. Percutaneous surgery is a good choice in the palliative management of spinal instability due to metastasis, being highly efficient and technically not challenging. Although the results of this study suggest that percutaneous surgery may play an important role in quickly improving quality of life and daily walking distance for patients with unstable spine metastasis, additional evidence is needed in the form of a larger prospective randomized cohort study of patients undergoing surgery for spinal metastases.

\section{References}

1. Abrahm JL, Banffy MB, Harris MB: Spinal cord compression in patients with advanced metastatic cancer: "all I care about is walking and living my life". JAMA 299:937-946, 2008

2. Aitken RC: Measurement of feelings using visual analogue scales. Proc R Soc Med 62:989-993, 1969

3. Bailar JC III, Gornik HL: Cancer undefeated. N Engl J Med 336:1569-1574, 1997

4. Barr JD, Barr MS, Lemley TJ, McCann RM: Percutaneous vertebroplasty for pain relief and spinal stabilization. Spine (Phila Pa 1976) 25:923-928, 2000

5. Bartels RHMA, van der Linden YM, van der Graaf WTA: Spinal extradural metastasis: review of current treatment options. CA Cancer J Clin 58:245-259, 2008

6. Burval DJ, McLain RF, Milks R, Inceoglu S: Primary pedicle screw augmentation in osteoporotic lumbar vertebrae: biomechanical analysis of pedicle fixation strength. Spine (Phila Pa 1976) 32:1077-1083, 2007
7. Choi D, Crockard A, Bunger C, Harms J, Kawahara N, Mazel C, et al: Review of metastatic spine tumour classification and indications for surgery: the consensus statement of the Global Spine Tumour Study Group. Eur Spine J 19:215-222, 2010

8. Choi D, Fox Z, Albert T, Arts M, Balabaud L, Bunger C, et al: Rapid improvements in pain and quality of life are sustained after surgery for spinal metastases in a large prospective cohort. Br J Neurosurg 30:337-344, 2016

9. Choma TJ, Frevert WF, Carson WL, Waters NP, Pfeiffer FM: Biomechanical analysis of pedicle screws in osteoporotic bone with bioactive cement augmentation using simulated in vivo multicomponent loading. Spine (Phila Pa 1976) 36:454-462, 2011

10. Chong S, Shin SH, Yoo H, Lee SH, Kim KJ, Jahng TA, et al: Single-stage posterior decompression and stabilization for metastasis of the thoracic spine: prognostic factors for functional outcome and patients' survival. Spine J 12:1083-1092, 2012

11. Coleman RE: Clinical features of metastatic bone disease and risk of skeletal morbidity. Clin Cancer Res 12:6243s6249s, 2006

12. Cortet B, Cotten A, Boutry N, Dewatre F, Flipo RM, Duquesnoy B, et al: Percutaneous vertebroplasty in patients with osteolytic metastases or multiple myeloma. Rev Rhum Engl Ed 64:177-183, 1997

13. Cotten A, Dewatre F, Cortet B, Assaker R, Leblond D, Duquesnoy B, et al: Percutaneous vertebroplasty for osteolytic metastases and myeloma: effects of the percentage of lesion filling and the leakage of methyl methacrylate at clinical follow-up. Radiology 200:525-530, 1996

14. Detmar SB, Muller MJ, Schornagel JH, Wever LDV, Aaronson NK: Health-related quality-of-life assessments and patient-physician communication: a randomized controlled trial. JAMA 288:3027-3034, 2002

15. Dittmer DK, Teasell R: Complications of immobilization and bed rest. Part 1: Musculoskeletal and cardiovascular complications. Can Fam Physician Médecin Fam Can 39:14281432, 1435-1437, 1993

16. Fairbank JCT: Oswestry disability index. J Neurosurg Spine 20:239-241, 2014

17. Fairbank JC, Couper J, Davies JB, O'Brien JP: The Oswestry low back pain disability questionnaire. Physiotherapy 66:271-273, 1980

18. Falicov A, Fisher CG, Sparkes J, Boyd MC, Wing PC, Dvorak MF: Impact of surgical intervention on quality of life in patients with spinal metastases. Spine (Phila Pa 1976) 31:2849-2856, 2006

19. Fan S, Hu Z, Zhao F, Zhao X, Huang Y, Fang X: Multifidus muscle changes and clinical effects of one-level posterior lumbar interbody fusion: minimally invasive procedure versus conventional open approach. Eur Spine J 19:316-324, 2010

20. Ferguson T, Rowlands AV, Olds T, Maher C: The validity of consumer-level, activity monitors in healthy adults worn in free-living conditions: a cross-sectional study. Int J Behav Nutr Phys Act 12:42, 2015

21. Filis AK, Aghayev KV, Doulgeris JJ, Gonzalez-Blohm SA, Vrionis FD: Spinal neoplastic instability: biomechanics and current management options. Cancer Contr 21:144-150, 2014

22. Fisher CG, DiPaola CP, Ryken TC, Bilsky MH, Shaffrey CI, Berven SH, et al: A novel classification system for spinal instability in neoplastic disease: an evidence-based approach and expert consensus from the Spine Oncology Study Group. Spine (Phila Pa 1976) 35:E1221-E1229, 2010

23. Fourney DR, Frangou EM, Ryken TC, Dipaola CP, Shaffrey CI, Berven SH, et al: Spinal instability neoplastic score: an analysis of reliability and validity from the spine oncology study group. J Clin Oncol 29:3072-3077, 2011 
24. Galasko CS: Skeletal metastases. Clin Orthop Relat Res (210):18-30, 1986

25. Galibert P, Deramond H, Rosat P, Le Gars D: [Preliminary note on the treatment of vertebral angioma by percutaneous acrylic vertebroplasty.] Neurochirurgie 33:166-168, 1987 $(\mathrm{Fr})$

26. Gerszten PC, Welch WC: Spine: minimally invasive techniques. Prog Neurol Surg 19:135-151, 2006

27. Ghogawala Z, Mansfield FL, Borges LF: Spinal radiation before surgical decompression adversely affects outcomes of surgery for symptomatic metastatic spinal cord compression. Spine (Phila Pa 1976) 26:818-824, 2001

28. Gilbert RW, Kim JH, Posner JB: Epidural spinal cord compression from metastatic tumor: diagnosis and treatment. Ann Neurol 3:40-51, 1978

29. Giorgi H, Blondel B, Adetchessi T, Dufour H, Tropiano P, Fuentes S: Early percutaneous fixation of spinal thoracolumbar fractures in polytrauma patients. Orthop Traumatol Surg Res 100:449-454, 2014

30. Hatrick NC, Lucas JD, Timothy AR, Smith MA: The surgical treatment of metastatic disease of the spine. Radiother Oncol 56:335-339, 2000

31. Helweg-Larsen S, Sørensen PS: Symptoms and signs in metastatic spinal cord compression: a study of progression from first symptom until diagnosis in 153 patients. Eur J Cancer 30A (3 30A):396-398, 1994

32. Ibrahim A, Crockard A, Antonietti P, Boriani S, Bünger C, Gasbarrini A, et al: Does spinal surgery improve the quality of life for those with extradural (spinal) osseous metastases? An international multicenter prospective observational study of 223 patients. J Neurosurg Spine 8:271-278, 2008

33. Itshayek E, Yamada J, Bilsky M, Schmidt M, Shaffrey C, Gerszten P, et al: Timing of surgery and radiotherapy in the management of metastatic spine disease: a systematic review. Int J Oncol 36:533-544, 2010

34. Jacobs WB, Perrin RG: Evaluation and treatment of spinal metastases: an overview. Neurosurg Focus 11(6):e10, 2001

35. Kim CH, Chung CK, Sohn S, Lee S, Park SB: Less invasive palliative surgery for spinal metastases. J Surg Oncol 108:499-503, 2013

36. Kobayashi K, Takeda F, Teramukai S, Gotoh I, Sakai H, Yoneda S, et al: A cross-validation of the European Organization for Research and Treatment of Cancer QLQ-C30 (EORTC QLQ-C30) for Japanese with lung cancer. Eur J Cancer 34:810-815, 1998

37. Kostuik JP, Errico TJ, Gleason TF, Errico CC: Spinal stabilization of vertebral column tumors. Spine (Phila Pa 1976) 13:250-256, 1988

38. Laufer I, Rubin DG, Lis E, Cox BW, Stubblefield MD, Yamada Y, et al: The NOMS framework: approach to the treatment of spinal metastatic tumors. Oncologist 18:744-751, 2013

39. Lee DY, Lee SH, Maeng DH: Two-level anterior lumbar interbody fusion with percutaneous pedicle screw fixation: a minimum 3-year follow-up study. Neurol Med Chir (Tokyo) 50:645-650, 2010

40. Lee JK, Jang JW, Kim TW, Kim TS, Kim SH, Moon SJ: Percutaneous short-segment pedicle screw placement without fusion in the treatment of thoracolumbar burst fractures: is it effective?: comparative study with open short-segment pedicle screw fixation with posterolateral fusion. Acta Neurochir (Wien) 155:2305-2312, 2013

41. Maranzano E, Bellavita R, Rossi R, De Angelis V, Frattegiani A, Bagnoli R, et al: Short-course versus split-course radiotherapy in metastatic spinal cord compression: results of a phase III, randomized, multicenter trial. J Clin Oncol 23:3358-3365, 2005

42. McHorney CA, Ware JE Jr, Raczek AE: The MOS 36-Item Short-Form Health Survey (SF-36): II. Psychometric and clinical tests of validity in measuring physical and mental health constructs. Med Care 31:247-263, 1993
43. Merom L, Raz N, Hamud C, Weisz I, Hanani A: Minimally invasive burst fracture fixation in the thoracolumbar region. Orthopedics 32:32, 2009

44. Moussazadeh N, Rubin DG, McLaughlin L, Lis E, Bilsky MH, Laufer I: Short-segment percutaneous pedicle screw fixation with cement augmentation for tumor-induced spinal instability. Spine J 15:1609-1617, 2015

45. Ni WF, Huang YX, Chi YL, Xu HZ, Lin Y, Wang XY, et al: Percutaneous pedicle screw fixation for neurologic intact thoracolumbar burst fractures. J Spinal Disord Tech 23:530-537, 2010

46. O'Toole JE, Eichholz KM, Fessler RG: Surgical site infection rates after minimally invasive spinal surgery. J Neurosurg Spine 11:471-476, 2009

47. Palmisani M, Gasbarrini A, Brodano GB, De Iure F, Cappuccio M, Boriani L, et al: Minimally invasive percutaneous fixation in the treatment of thoracic and lumbar spine fractures. Eur Spine J 18 (Suppl 1):71-74, 2009

48. Papanastassiou ID, Filis AK, Gerochristou MA, Vrionis FD: Controversial issues in kyphoplasty and vertebroplasty in malignant vertebral fractures. Cancer Contr 21:151-157, 2014

49. Pascal-Moussellard H, Broc G, Pointillart V, Siméon F, Vital JM, Sénégas J: Complications of vertebral metastasis surgery. Eur Spine J 7:438-444, 1998

50. Quan GMY, Vital JM, Aurouer N, Obeid I, Palussière J, Diallo A, et al: Surgery improves pain, function and quality of life in patients with spinal metastases: a prospective study on 118 patients. Eur Spine J 20:1970-1978, 2011

51. Rades D, Huttenlocher S, Bajrovic A, Karstens JH, Adamietz IA, Kazic N, et al: Surgery followed by radiotherapy versus radiotherapy alone for metastatic spinal cord compression from unfavorable tumors. Int J Radiat Oncol Biol Phys 81:e861-e868, 2011

52. Schiff D, O’Neill BP, Suman VJ: Spinal epidural metastasis as the initial manifestation of malignancy: clinical features and diagnostic approach. Neurology 49:452-456, 1997

53. Schmidt OI, Strasser S, Kaufmann V, Strasser E, Gahr RH: Role of early minimal-invasive spine fixation in acute thoracic and lumbar spine trauma. Indian J Orthop 41:374-380, 2007

54. Schwab JH, Gasbarrini A, Cappuccio M, Boriani L, De Iure F, Colangeli S, et al: Minimally invasive posterior stabilization improved ambulation and pain scores in patients with plasmacytomas and/or metastases of the spine. Int J Surg Oncol 2011:239230, 2011

55. Sciubba DM, Petteys RJ, Dekutoski MB, Fisher CG, Fehlings MG, Ondra SL, et al: Diagnosis and management of metastatic spine disease. A review. J Neurosurg Spine 13:94108,2010

56. Snyder CF, Blackford AL, Brahmer JR, Carducci MA, Pili $\mathrm{R}$, Stearns V, et al: Needs assessments can identify scores on HRQOL questionnaires that represent problems for patients: an illustration with the Supportive Care Needs Survey and the QLQ-C30. Qual Life Res 19:837-845, 2010

57. Tokuhashi Y, Ajiro Y, Umezawa N: Outcome of treatment for spinal metastases using scoring system for preoperative evaluation of prognosis. Spine (Phila Pa 1976) 34:69-73, 2009

58. Tokuhashi Y, Matsuzaki H, Toriyama S, Kawano H, Ohsaka S: Scoring system for the preoperative evaluation of metastatic spine tumor prognosis. Spine (Phila Pa 1976) 15:1110-1113, 1990

59. Tomita K, Kawahara N, Kobayashi T, Yoshida A, Murakami H, Akamaru T: Surgical strategy for spinal metastases. Spine (Phila Pa 1976) 26:298-306, 2001

60. Vanek P, Bradac O, Konopkova R, de Lacy P, Lacman J, Benes V: Treatment of thoracolumbar trauma by short-segment percutaneous transpedicular screw instrumentation: prospec- 
tive comparative study with a minimum 2-year follow-up. J Neurosurg Spine 20:150-156, 2014

61. Walker MP, Yaszemski MJ, Kim CW, Talac R, Currier BL: Metastatic disease of the spine: evaluation and treatment. Clin Orthop Relat Res 415 Suppl:S165-S175, 2003

62. Wang H, Zhou Y, Li C, Liu J, Xiang L: Comparison of open versus percutaneous pedicle screw fixation using the sextant system in the treatment of traumatic thoracolumbar fractures. Clin Spine Surg [epub ahead of print], 2016

63. Weber MH, Burch S, Buckley J, Schmidt MH, Fehlings MG, Vrionis FD, et al: Instability and impending instability of the thoracolumbar spine in patients with spinal metastases: a systematic review. Int J Oncol 38:5-12, 2011

64. Wild MH, Glees M, Plieschnegger C, Wenda K: Five-year follow-up examination after purely minimally invasive posterior stabilization of thoracolumbar fractures: a comparison of minimally invasive percutaneously and conventionally open treated patients. Arch Orthop Trauma Surg 127:335-343, 2007

65. Wu J, Zheng W, Xiao JR, Sun X, Liu WZ, Guo Q: Health-related quality of life in patients with spinal metastases treated with or without spinal surgery: a prospective, longitudinal study. Cancer 116:3875-3882, 2010

\section{Disclosures}

Withings Pulse Ox activity monitoring devices to assess walking distance were provided by Withings.

\section{Author Contributions}

Conception and design: Bernard. Acquisition of data: Bernard. Analysis and interpretation of data: Bernard, Lucas. Drafting the article: Bernard. Critically revising the article: Menei. Reviewed submitted version of manuscript: Menei. Approved the final version of the manuscript on behalf of all authors: Bernard. Statistical analysis: Lemée. Study supervision: Lucas.

\section{Correspondence}

Florian Bernard, Service de Neurochirurgie, CHU, 4 rue Larrey, Angers 49100, France. email: bernardflorian.bf@gmail.com. 